Abdrashev, R.M., Dyusebayev, T.T., \& Akimbayeva, A.A. (2021). Legal status of an expert in criminal proceedings of the Republic of Kazakhstan. The Law and its Interpretation. Collection of Scientific Articles. European Scientific e-Journal, 5 (11), 46-56. Hlučín-Bobrovníky: "Anisiia Tomanek" OSVČ. (in Russian) Аблрашев, Р.М., Аюсебаев, Т.Т., Акимбаева, А.А. (2021). Правовой статус эксперта в уголовном судопроизводстве Республики Казахстан. The Law and its Interpretation. Collection of Scientific Articles. European Scientific e-Journal, 5 (11), 46-56. Hlučín-Bobrovníky: “Anisiia Tomanek” OSVČ.

DOI: 10.47451 /jur2021-03-001

EOI: 10.11244/jur2021-03-001

The paper is published in Crossref, Internet Archive, Google Scholar, Academic Resource Index ResearchBib, JGate, ISI, CiteFactor, ICI, eLibrary databases.

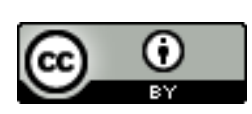

Ruslan M. Abdrashev

Doctor of Law, Professor

Department of Criminal Law and Law Enforcement

D.A. Kunaev Eurasian Law Academy

Almaty, Kazakhstan

E-mail: rusabdr@mail.ru

Talgat T. Dyusebayev

Doctor of Philosophy in Law (PhD), Associate Professor Department of Criminal Law and Law Enforcement

D.A. Kunaev Eurasian Law Academy

Almaty, Kazakhstan

E-mail: dussebaev-talgat@bk.ru

Ainur A. Akimbayeva

Master of Science in Law

Taraz Innovation and Humanities University

Taraz, Kazakhstan

E-mail: ainura-akimbaeva@mail.ru

\title{
Legal status of an expert in criminal proceedings of the Republic of Kazakhstan
}

\section{Abstract:}

The article reveals the problematic issues of the appointment and production of forensic examinations in the criminal procedure legislation of the Republic of Kazakhstan. The authors of the article analyzed the norms of the criminal procedure law, as well as the current state of judicial and investigative practice on the appointment of expert examinations. In the process of analyzing the criminal procedure law, a comparison of the legal status of 'expert and specialist' in the legislation of Kazakhstan was also made. The analysis will allow the legislators of the post-Soviet countries to take into account the shortcomings described in the construction of the norms of the criminal procedure law. For example, an analysis of the norms of the criminal procedure law shows that today the expert is deprived of the opportunity to go beyond the list of questions. The foregoing leads to the fact that some aspects important for the investigation remain without consideration. This negatively affects the resolution of the tasks of the criminal procedure law. 
Keywords:

expert, specialist, forensic examination, legal status, pre-trial proceedings.

УАK: 343.1(574)

\author{
Руслан Муратханович АбАрашев \\ Аоктор юридических наук, профессор \\ Кафедра «Уголовного права и правоохранительной деятельности» \\ Евразийская Юридическая Академия им. А.А. Кунаева \\ Алматы, Республика Казахстан \\ E-mail: rusabdr@mail.ru \\ Талгат Турашевич Ансебаев \\ Аоктор философии в области права (PhD), Аоцент \\ КафеАра «Уголовного права и правоохранительной деятельности» \\ Евразийская Юридическая Академия им. А.А. Кунаева \\ Алматы, Республика Казахстан \\ E-mail: dussebaev-talgat@bk.ru \\ Айнур Аџимхановна Акимбаева \\ магистр юридических наук \\ Таразский инновационно-гуманитарный университет \\ Тараз, Республика Казахстан \\ E-mail: ainura-akimbaeva@mail.ru
}

\title{
Правовой статус эксперта в уголовном судопроизводстве Республики Казахстан
}

\section{Aннотачия:}

В статье раскрыты проблемные вопросы назначения и производства судебных экспертиз в уголовно-процессуальном законодательстве Республики Казахстан. Авторы статьи проанализировали нормы уголовно-процессуального закона, а также современное состояние судебно-следственной практики по вопросам назначения экспертиз. В процессе анализа уголовно-процессуального закона также проведено сравнение правового статуса «эксперта и специалиста» в законодательстве Казахстана. Проведенный анализ позволит законодателям стран постсоветского периода учесть изложенные недостатки в конструировании норм уголовно-процессуального закона. К примеру, анализ норм уголовно-процессуального закона показывает, что на сегодняшний день эксперт мишен возможности выходить за перечень вопросов, которые указывает в постановлении следователь. Изложенное влечет к тому, что некоторые важные Аля расследования аспекты остаются без рассмотрения. Это негативным образом влияет на разрешение задач уголовнопроцессуального закона.

\section{Kлючевые слова:}

эксперт, специалист, судебная экспертиза, правовой статус, Аосудебное производство. 


\section{Вступление}

Вступившие в силу с 1 января 2015 г. новый Уголовный и Уголовнопроцессуальный кодексы Республики Казахстан кардинальным образом изменили преАставление о правовой системе Казахстана, которая в настоящее время существенным образом отличается от правовых систем стран постсоветского периода, которая в настоящее время представ яяет собой своеобразный микс англо-саксонской и романо-германской систем права. С принятием нового уголовно-процессуального закона видоизменились многие традиционные институты уголовно-процессуального права. Впервые в Республике Казахстан сделан шаг по Аиквидации стадии возбуждения уголовного Аела, существенному упрощению предварительного расследования, введению новых правовых институтов и норм, ранее не характерных Аля отечественной правовой системы (Уголовно-процессуальный кодекс Республики Казахстан от 04.07.2014).

Безусловно, законодательное решение, направленное на миквидацию стаАии возбужАения уголовного Аела, стало неожиданным Аля юриАической общественности - как А^я теории уголовного процесса, так и А^я правоприменительной деятельности. Изменилась роль и значение судебной экспертизы в решении задач уголовного судопроизводства.

Целью исследования является выявление проблем правового регулирования Аеятельности судебного эксперта в уголовном судопроизводстве Казахстана. А^я выполнения этой цели авторы предлагают решить следующие задачи:

- исследователь роль судебной экспертизы в решении задач уголовного судопроизводства;

- исследователь правовой статус эксперта в уголовном судопроизводстве Казахстана;

- исследовать соотношение понятий «заключение эксперта» и «заключение специалиста».

В работе использованы следующие общенаучные методы: Аиалектический, анализ и синтез составных частей, отАельных категорий, обобщение и классификация. Из специальных методов правовых исслелований были использованы: сравнительно-правовой, психологический, социологический, исторический, системно-структурный, формально-

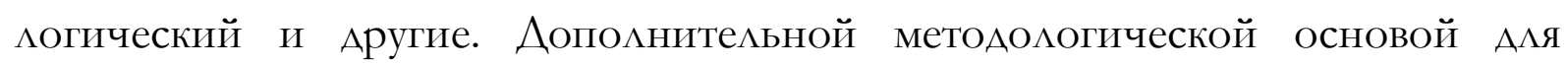


выработки научных категорий явились законы формальной Аингвистики.

Авторы опирались на исследования, проведенные авторами, указанными

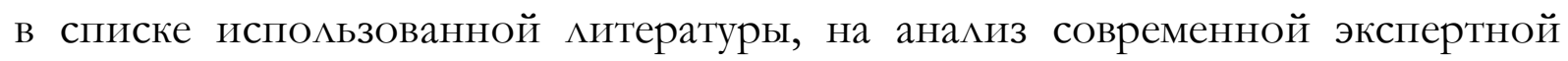
практики, а также на Уголовно-процессуальный кодекс Республики Казахстан.

\section{Проблемы правового регулирования деятельности эксперта в уголовно- процессуальном законе Респубиики Казахстан}

За последнее время в юридической Аитературе появицось много работ, в которых рассматриваются вопросы специальных знаний в раскрытии, расследовании и предупреждении различных видов преступлений. Основные положения института специальных знаний Аостаточно подробно были исследованы в работах, как казахстанских, так и зарубежных процессуалистов и криминалистов. Среди многочисленных исследований можно вылелить труды Т.В. Аверьяновой, А.Е. Ароцкер, А.Ф. Аубакирова, Р.С. Белкина, Б.М. Бишманова, Ж.Р. Аильбархановой, А.Н. Васильева, С.П. Варениковой, А.Р. Волынского, А.Я. Гинзбурга, В.И. Гончаренко, Е.Г. Ажакишева, А.В. Аулова, С.Е. Еркенова, А.М. Зинина, Е.П. Ищенко, А.А. Исаева, В.Я. КолАина, В.К. Аисиченко, Н.Т. Майлис, С.П. Митричева, В.А. Образцова, И.А. Петрухина, Е.Р. Россинской, Н.А. Селиванова, М.С. Строговича, Г.И. Поврезнюка, Б.Х. Толеубековой, К.Н. Шакирова и Аругих.

Указанные исследователи внесли достаточно большой вклаА в науку криминалистику и уголовно-процессуальное право. Вместе с тем, в юридической митературе содержатся разцичные трактовки специальных знаний. Несмотря на это, «...все авторы едины в том мнении, что это знания в науке, технике искусстве или ремесле, и Аля их применения необходимы как знание предмета, так и профессионацьный опыт, умение использовать научнотехнические средства и методы Аля обнаружения, фиксации, изъятия и исследования доказательств, оказания различных виАов помощи следователю, работнику органа Аознания в раскрытии и расследовании преступлений» (Петрунина, 2006, 158).

Верно отмечено А.Н. Оркиным: «...Ая обнаружения, собирания, исследования и оценки доказательств общих юридических познаний чаще всего оказывается недостаточно» (Оркин, 1988, с. 3). Высококвалифицированное расследование преступлений трудно преАставить без использования специальных знаний. В связи с интенсивным развитием в настоящее время науки и техники возникают новые вилы профессиональной 
деятельности человека, что порожАает новые специальности и возможности Аля слеАственной и судебной практики по использованию специальных знаний в Аоказывании (Коваценко, 1990, 7).

Аействующее у уголовно-процессуальное

законодательство предусматривает возможность использования двух направ ений специальных знаний в форме участия специалистов в производстве следственных действий и оперативно-розыскных мероприятий; производства экспертиз. «В криминалистической митературе отмечается, что выбор той или иной формы специальных познаний должен быть тактически обоснован. В первую очередь необходимо учитывать существенность устанавливаемого факта. Если факт, устанавливаемый с использованием специальных познаний, является доказательственным, т.е. может быть использован как аргумент в процессе последующего Аоказывания, как среАство подтвержАения или искАючения выАвинутых при расследовании версий и особенно когда признакам, на основе которых этот факт устанавцивается, может быть дано разАичное объяснение, необходимо производство экспертизы» (Криминалистика, 2001, 374).

Несмотря на важность применения специальных знаний в раскрытии и расследовании преступлений, в связи с принятием УПК Республики Казахстан обострились противоречия, связанные с использованием законодателем понятийного аппарата.

Предлагаем поэтапно разобраться в проблемах правового регулирования Аеятельности судебного эксперта, начиная с изменений в стадиях уголовного процесса.

Вопрос о Аопустимости производства экспертизы, как и ряда Аругих следственных действий, в стадии возбуждения уголовного дела дискутировался на протяжении нескольких десятилетий.

Высказыва^ись различные, порой диаметра^ьно противоположные точки зрения. ОАни авторы были за максимальное расширение перечня следственных Аействий, Аопустимых на этой стаАии, поскольку это обеспечивает быструю и качественную предварительную проверку и достоверность её результатов, а следовательно, законность и обоснованность возбужАения уголовного Аела. Аругие категорически против этого возражали, поскольку такое расширение ведет, по их мнению, к стиранию грани межАу стадиями возбужАения уголовного дела и предварительного расследования.

Новый Уголовно-процессуальный кодекс Республики Казахстан, с одной стороны, разрешил эту проблему, а с Аругой - создац ряА Аругих проблем, в том числе и коллизионного характера. Аиквидация стаАии возбуждения 
уголовного в новом УПК Республики Казахстан изменило преАставление о понятии, сущности и значении судебной экспертизы в уголовном процессе, которая в ст. 184 утратившего сику УПК Республики Казахстан, наряду с осмотром, выемкой предметов и Аокументов, относицась к слеАственным Аействиям, производство которых было Аопустимо Ао возбужАения уголовного дема.

При этом обоснованием производства рассматриваемых следственных Аействий АО возбужАения уголовного Ае а яв яя ось отсутствие в них элемента существенного ущемления конституционных прав гражАан. Если стадия возбужления уголовного дела представ яя своего рода фильтр Аля принятия законных процессуальных решений, то судебная экспертиза выполняла роль средства, необходимого Аля обеспечения законности при принятии процессуальных решений по уголовным делам.

С Аругой стороны, Аалеко не каждая судебная экспертиза могла быть назначена на Аанной стадии. Очевидно, например, что недопустимо проведение судебно-психиатрической экспертизы, поскольку она сопряжена с множеством весьма существенных ограничений (помещение в стационар и пр.), Аа и по времени она может быть очень продолжительной. Помимо изцоженного, помещаемый в стационар на момент назначения экспертизы не имел никакого правового статуса, а значит, был бесправным. Уголовнопроцессуальному колексу Республики Казахстан был известен только правовой статус подозреваемого Аица. Как же разрешен этот вопрос в новом УПК?

В настоящее время судебная экспертиза теряет свое предназначение, поскольку в новом Уголовно-процессуальном кодексе (ст. 179 УПК РК) началом Аосудебного расследования (ранее использовался термин «предварительное расследование») является регистрация заявления, сообщения об уголовном правонарушении в ЕАином реестре Аосудебных расследований Аибо проведение первого неотложного слеАственного Аействия. Отсутствие конкретизации следственных действий указывает на то, что следователь уполномочен провести Аюбые неотложные слеАственные Аействия, в том числе использовать анацог судебной экспертизы - заключение специалиста.

Очередной новелцой в уголовном судопроизводстве Казахстана является введение института слелки о признании вины, а также упрощенной формы производства по уголовному Аелу. В качестве негативных последствий, которые могут последовать, отмечается возможность самооговора обвиняемого, решение вопросов виновности мица уже на стадии 
предварительного расследования. В этой связи возможны формализм в сборе фактических Аанных, адаптация следователя к ускоренным процедурам производства предварительного следствия путем замены одних следственных или процессуальных Аействий Аругими (в нашем случае заключения эксперта на заключение специалиста).

Аля уголовного судопроизводства Казахстана Аолгое время были характерны такие формы предварительного расследования, как предварительное следствие и дознание. На сегодняшний день (с момента принятия нового УПК РК) предварительное расследование может быть окончено в таких формах, как: досудебное расследование в форме дознания; предварительного следствия; протокольной форме. Большую популярность в практической деятельности приобретает ускоренное Аосудебное расследование по уголовным делам. В качестве негативного момента можно отметить возможность проведения ускоренного досудебного расследования по тяжким преступлениям, если собранными доказательствами установлены факт преступ ения и совершившее его Аицо, полное признание им своей вины, согласие с размером (суммой) причиненного ущерба (вреАа) (ст. 190 УПК РК).

Принимая во внимание обязательные сроки проведения ускоренного досудебного расследования (Аолжно быть закончено в течении 15 суток), прогнозируется тенденция к максимальному использованию специальных знаний в форме заключения специалиста, как аналог заключению эксперта. Таким образом, применение специальных научных знаний (посредством назначения соответствующих видов судебных экспертиз) в ряде случаев отходит на второй план, приводя к вероятности Аопущения судебных и следственных ошибок.

Сравнительно-правовой анализ понятий «закцючение эксперта» и «заключение специалиста» показывает, что законодатель не дает полного определения вышеуказанным понятиям, называя их документами. Вместе с тем, Аоказательственное значение заключения специалиста выглядит убедительнее, поскольку под ним понимается официацьный документ. Как известно, грамматическое значение «официального Аокумента» в русском языке очень многообразно. Чаще всего, поА ним понимается документ, составленный, выданный или находящийся в обороте государственных органов, учреждений, организаций и предприятий, отвечающий определенным требованиям.

Анализ правоприменительной деятельности органов уголовного преследования свидетельствует о недооценке и негативном отношении субъектов правоприменения к заключению специалиста, как одному из виАов 
фактических данных по уголовным Аелам. Первым шагом, свидетельствующим о придании важности доказательственного значения заключения специалиста, стало внесение изменений в ст. 84 УПК РК от 13 Аекабря 1997 г., предусматривающих уголовную ответственность специалиста в случае заведомо Аожного заключения. В последующем, в ч. 2 ст. 111 нового УПК РК закАючение специалиста, наряду с Аругими фактическими Аанными (в том числе и с заключением эксперта), законодательно отнесено к разновидности доказательств по уголовным делам.

Таким образом, законодатель разрешил дискуссионные вопросы, связанные с признанием заключения специалиста в качестве Аоказательства по уголовным делам. Исходя из нововведений, возникает вопрос, не ставит ми законодатель знак тождества между понятиями «специацьные знания» и «специальные научные знания»? Несмотря на огромную значимость судебной экспертизы в проведении быстрого и полного раскрытия и расследования уголовных правонарушений, необходимо отметить, что как в доктрине, так и в правоприменительной практике судебно-экспертной Аеятельности остается множество Аискуссионных вопросов относительно правового статуса эксперта.

В настоящее время эксперт выступает в качестве самостоятельного субъекта уголовного процесса, обладающего собственными процессуальными обязанностями и правами, которые отличают его от иных субъектов права. В новом УПК, как и в УПК РК от 13 декабря 1997 г., исходя из смысла ст. 79 УПК РК, экспертом является незаинтересованное в деле мицо, обладающее специальными научными знаниями (хотя по мнению ряда ученых, разграничение специальных знаний и специальных научных знаний формацьно). При этом правовой статус эксперта, изложенный в ст. 79 нового УПК РК, полностью воспроизводит положения ст. 83 УПК РК от 13 Аекабря 1997 г. (Уголовно-процессуальный кодекс Республики Казахстан от 04.07.2014).

Аицо, привлекаемое в качестве эксперта, Аолжно соответствовать таким признакам, как отсутствие заинтересованности в исходе дела, а также наличие специальных научных знаний. В отличие от процессуального положения дознавателя, следователя, судьи, в отношении которых законодатель оперирует термином «независимость», правовой статус эксперта в УПК РК явно ограничен, что указывает на формальность участия эксперта в реализации задач уголовного судопроизводства (беспристрастное, быстрое и полное раскрытие и расследование уголовных правонарушений). 
ОАнако, право на инициативные действия, несомненно, занимает важное место в системе прав эксперта при производстве экспертизы. Но, как всякое право, оно останется чисто декларативным, если закон не предусмотрит мер реализации этого права, если ему не будут соответствовать чьи-то обязанности по реализации инициативных предложений эксперта. Так, в соответствии с гипотезой, указанной в п. 5 ч. 3 нового УПК РК эксперт, по согласованию с органом, назначившим экспертизу, в пределах своей компетенции вправе Аавать заключение по выявленным в ходе судебно-экспертного исследования обстоятельствам, имеющим значение Аля Аела, выходящим за пределы вопросов, содержащихся в постановлении о назначении судебной экспертизы. В свою очередь, нежелание следователя согласовывать постановку Аополнительных вопросов можно расценивать как наложение запрета на экспертную инициативу. Эксперт не может выйти за пределы поставленных ему на разрешение вопросов, тем самым устранить недостаточно компетентную формулировку вопросов со стороны следователя.

Таким образом, на основании изложенного мы пришли к следующим выводам. На сегодняшний день уголовно-процессуальное законодательство

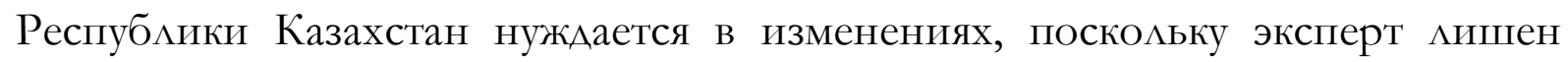
возможности выходить за пределы тех вопросов, которые излагаются следователями при назначении судебных экспертиз. В этой связи часть 1 ст. 79 УПК Республики Казахстан изложить в следующей редакции: «1. В качестве

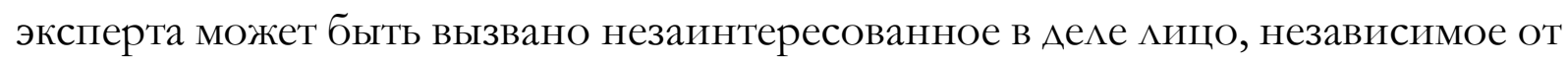
органов уголовного преследования и обладающее специальными научными знаниями. Иные требования, предъяв яемые к мицу, которому может быть поручено производство экспертизы, устанавАиваются частью первой ст. 273 настоящего Кодекса».

\section{Закиючение}

Таким образом, несмотря на принятие нового УПК Республики Казахстан, многие процессуальные вопросы, связанные с правовым статусом эксперта и специалиста, назначением и производством экспертиз, остались неразрешенными. В первую очередь, хотелось бы отметить ошибки законодателя при конструкции дефиниции «заключение специалиста». Полагаем о нелогичности включения в определение «заключении специалиста» понятие «официального Аокумента», поскольку такая трактовка Аает преимущество заключению специалиста перед заключением эксперта. Заключение эксперта всегла имело приоритет перед заключением специалиста 
при оценке фактических данных по уголовным делам. В первую очередь, это обусловлено тем, что заключение эксперта представ яет собой проведение исследования мицом, имеющим специальные научные знания, тогда как заключение специалиста исходит от мица, не обладающими специальными научными знаниями. Знания специациста ограничиваются специальными не научными познаниями, в связи с чем заключение эксперта всегда выглядит убедительней. В этой связи мы предлагаем разработать новые дефиниции «заключение специалиста» и «заключение эксперта» через призму специальных научных знаний и специальных познаний. Это позволит разрешить Аискуссионные вопросы уголовно-процессуального кодекса Республики Казахстан, который необоснованно отдает предпочтение заключению специалиста при оценке доказательств по уголовным делам. Мы не претендуем на безупречность сделанных выводов, однако полагаем, что предложенные нами рекомендации и выводы представят интерес Аля специалистов в области уголовно-процессуального права и судебной экспертизы.

\section{Список источников информации:}

Абрашев, Р.М., Бекбасарова, Т.Ж. (2015). Аискуссионные вопросы применения специальных научных знаний в контексте принятия нового уголовно-процессуального кодекса Республики Казахстан. Вестник Сибирского торидческого института ФСКН России, 4 (21), 56-59.

Алимова, Э.А. (2019). Проблемы участия специалиста в современном уголовном процессе Республики Казахстан. Вестник криминалистики, 1 (69), $59-66$.

Коваленко, Е.Г. (1990). Использование экспертньгх знаний в деятельности органов внутренних дел по предупреждению хищений сочиалистического имущества: Учебное пособие. Киев: КВШ МВА СССР им Ф.Э. Азержинского.

Кодекс Республики Казахтан. Уголовно-процессуальный кодекс Республики Казахстан от 4 июля 2014 года № 231-V (с изменениями и Аополнениями по состоянию на 04.09.2021 г.)

Оркин, А.Н. (1988). Использование спещиальнъхх познаний при расследовании пожаров. Хабаровск: Хабаровская высшая школа МВА СССР.

Петрунина, А.Б. (2006). Противодействие расследованию преступлений в сфере незаконного оборота наркотиков и криминалистические методы его въгявления и преодоления. Аиссертация канА. юриА. наук. Москва. 
Русалова, Н.С. (2020). Особенности правового регулирования назначения и производства судебных экспертиз в уголовном судопроизводстве России и Республики Казахстан. Вестник Уральского юридического института МВА России, 1 (25), 9-14. Уголовно-процессуальный кодекс Республики Казахстан от 04.07.2014: Практическое пособие (2015). Алматы: «ИзАательство «Норма-К».

Шакиров, К. (2016). Судебная экспертология: проблемв и ремения (от теории практике). Алматы: Қазақ университеті.

Яблоков, Н.П. (ред.) (2001). Криминалистика: Уиебник. 2-е издание. Москва: Юристь. 